\title{
The association between consumption of breakfast cereals and BMI in schoolchildren aged 12-17 years: The VYRONAS study
}

\author{
Rena I Kosti ${ }^{1, *}$, Demosthenes B Panagiotakos ${ }^{2}$, Antonis Zampelas ${ }^{1}$, Costas Mihas ${ }^{3}$, \\ Alevizos Alevizos ${ }^{4}$, Clare Leonard ${ }^{5}$, Yannis Tountas ${ }^{3}$ and Anargiros Mariolis ${ }^{4}$ \\ 'Unit of Human Nutrition, Department of Food Science and Technology, Agricultural University of Athens, 75 \\ lera Odos, 1 1855, Athens, Greece: ${ }^{2}$ Department of Nutrition - Dietetics, Harokopio University, Athens, Greece: \\ ${ }^{3}$ Department of Hygiene and Epidemiology, School of Medicine, University of Athens, Athens, Greece: \\ ${ }^{4}$ Department of General Practice and Family Medicine, Health Center of Vyronas, Athens, Greece: ${ }^{5}$ Cereal \\ Partners Worldwide, Lausanne, Switzerland
}

Submitted 16 March 2007: Accepted 26 September 2007: First published online 20 December 2007

\begin{abstract}
Objective: To evaluate whether consumption of breakfast cereals is associated with BMI in a sample of Greek adolescents.

Design: A cross-sectional health and nutrition survey.

Setting and subjects: During 2004-5, 2008 schoolchildren aged 12-17 years were selected from twelve schools located in Vyronas region (Athens metropolitan area). Height and weight were measured and BMI was calculated. A semiquantitative FFQ was applied and multiple logistic regression analysis was used. Results: Overall, $4 \cdot 7 \%$ of boys and $1.7 \%$ of girls were obese, whereas $19 \cdot 4 \%$ of boys and $13 \cdot 2 \%$ of girls were overweight. Only $20 \cdot 7 \%$ of boys and $15 \cdot 5 \%$ of girls reported that they consume cereals as a first choice for breakfast. Consumption of breakfast cereals was associated with lower BMI in boys $(P=0 \cdot 08)$ and girls $(P=0 \cdot 019)$, irrespective of age and physical activity status. More prominent results were observed for daily cereal consumption or for more than two daily servings of cereals consumed for breakfast. Consumption of pre-sweetened breakfast cereals was associated with lower BMI compared with non-pre-sweetened or no intake of cereals, in both genders $(P<0 \cdot 001)$. Consumption of breakfast cereals was associated with 33\% (95\% CI 14\%, 48\%) lower likelihood of overweight/obesity, irrespective of age, sex and physical activity status.

Conclusions: Consumption of breakfast cereals was associated with lower BMI levels and a lower likelihood of overweight/obesity in both genders; thus a solid basis for public health professionals could be built when issuing advice on weight management.
\end{abstract}

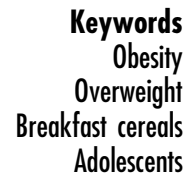

The prevalence and severity of overweight are increasing in children and adolescents, and its short- and long-term associations with morbid outcomes raises the level of importance for understanding overweight as a major public health concern for in this age group ${ }^{(1)}$. In Greece, the prevalence of obesity in adults, children and adolescents has been evaluated recently by some investigators $^{(2-5)}$. Moreover, research ${ }^{(6)}$ shows that the dietary habits of Greek adults have changed towards a more Westernised type of diet, with some indication of this also being valid for children and adolescents ${ }^{(7,8)}$. The Westernisation of eating habits includes a reduced intake of dietary fibre, an increased intake of simple sugars and refined grain products, altered fat composition of the diet and a dietary pattern characterised by a high glycaemic $\operatorname{load}^{(9)}$. One dietary pattern that is considered to play an important role in maintaining normal weight and providing positive nutritional benefits in children and adolescents is the consumption of breakfast ${ }^{(10)}$. Research ${ }^{(11)}$ reveals that not only is breakfast consumption important, but also that the type of breakfast may be an important factor influencing BMI. Eating cereal, whether cooked or ready to eat for breakfast, is associated with a significantly lower BMI in adults, when compared with either skipping breakfast or consuming other types of breakfast ${ }^{(11)}$. Studies ${ }^{(12-20)}$ have demonstrated the nutritional benefits of ready-to-eat breakfast cereals (RTEC) in nutrient intakes in both children and adolescents. During the past few years, several investigators ${ }^{(11-13,17,19-22)}$ have observed an inverse association between consumption of breakfast cereals and the rate of obesity in adults and adolescents. Moreover, other researchers ${ }^{(23,24)}$ report that this 
association is attributable only to the consumption of whole-grain cereals and not to refined-grain ones. However, there is only one study ${ }^{(13)}$ looking at the effects of adolescents' RTEC consumption on BMI in Greece.

Therefore the aim of the present work, which was performed within in the context of the VYRONAS epidemiological study, was to investigate whether the prevalence of overweight and obesity in 12-17-year-old boys and girls from the greater Athens area is associated with the consumption of breakfast cereals.

\section{Methods}

\section{Study sample}

In the VYRONAS study, 2008 students (1021 male and 987 female), 12-17 years of age ( 7 th-12th grade), were selected from all schools, a total of twelve, located in Vyronas region (Athens metropolitan area). The participation rate was $95 \%$. The adolescents were enrolled on a voluntary basis. Prior to their acceptance, the adolescents' parents or guardians were fully informed about the objectives and methods of the study and signed a consent form. The adolescents provided their verbal assent. Subjects who were on specific diets and/or who did not have medical permission to participate in physical activities were excluded from the study. The data were collected from September 2004 to May 2005.

We selected the region of Vyronas owing to the representativeness of this area regarding the socioeconomic status of the citizens. First, the municipality of Vyronas is of medium size (National Population Inventory Report) and thus represents an 'average' region of the Athens metropolitan area. Second, Vyronas includes all socio-economic classes (according to the National Population Inventory Report) and is therefore a close representation of the capital's population in terms of social status. The number of enrolled children was adequate (i.e. statistical power $80 \%$ ) to evaluate standardised differences between various groups greater than 0.5 at a probability level of $<0 \cdot 05$.

All children completed a questionnaire, developed for the purposes of the study, which retrieved information about age, sex, school class, dietary habits and physical activity.

\section{Measurements}

We measured standing height using stadiometers (Raven Equipment Limited, Essex, UK), to the nearest $0.1 \mathrm{~cm}$, with students wearing light clothing and without shoes; and body weight, of fasting students, to the nearest $0.1 \mathrm{~kg}$ on calibrated digital scales (Seca, Hanover, Germany). Stadiometers and scales were calibrated periodically. Measurements took place in the school setting before the interview. Eight trained physicians and dietitians were responsible for measuring body weights and heights.
Overweight and obesity were defined using the international BMI cut-off points established for children and youth $^{(25)}$. These cut-off points are based on health-related adult definitions of overweight $\left(\geq 25 \mathrm{~kg} / \mathrm{m}^{2}\right)$ and obesity $\left(\geq 30 \mathrm{~kg} / \mathrm{m}^{2}\right)$ but are adjusted to specific age and sex categories for children. Complete growth measurements were recorded in 1021 boys and 987 girls ( $n$ 2008). Selfreported body weight and height of both parents were recorded, and BMI was calculated as well. Parents were classified as normal-weight, overweight (BMI = $\left.25 \cdot 0-29 \cdot 9 \mathrm{~kg} / \mathrm{m}^{2}\right)$ or obese $\left(\mathrm{BMI} \geq 30 \cdot 0 \mathrm{~kg} / \mathrm{m}^{2}\right)$.

The VYRONAS survey also included a semi-quantitative FFQ that was distributed to all adolescents, which gathered information regarding the participants' dietary habits on a daily or weekly basis. The FFQ has been found to be repeatable in previous uses (data not published). The subjects were asked to recall the dietary habits which they had followed for the past year. Before completing the FFQ, an explanatory session on how the FFQ had to be filled out was given by dietitians.

Thereafter, the interviewer went through the food list again to clarify entries. To improve the accuracy of food descriptions, standard household measures (cups, tablespoons, portions, cans, etc.) and picture models were used during interviews to define amounts when appropriate. Various foods and beverages usually consumed in Greece, and habits pertaining to mealtime behaviours, were recorded in sixty-three detailed descriptive questions.

In particular, the measurements included the following.

1. The frequency of breakfast consumption (never/rare, 1-2 times/week, 3-4 times/week, 5-6 times/week, daily).

2. The types of foods consumed for breakfast as a first choice (milk, cereals, fruit juice, cake/croissant, butter/margarine, bread, honey and yoghurt, which are included in the typical Greek breakfast), the type of cereals consumed for breakfast being:

(i) pre-sweetened by the manufacturer (cereals with added sugars or other sweetening substances such as chocolate);

(ii) non-pre-sweetened by the manufacturer.

3. The frequency of cereals consumption for breakfast (never/rare, 1-3 times/month, 1 time/week, 2-6 times/week, daily, $>2$ daily servings of cereals for breakfast, taking into account that 1 serving of cereals $\approx 40 \mathrm{~g}$ ).

4. The daily consumption of meals including snacks (eating episodes).

5. The frequency of consumption of foods out of home (including school canteens and other meals not prepared at home).

6. The cooking method most often used by the family.

7. The weekly or daily intake of dairy products.

8. The type of oils/fat consumed.

9. The frequency of sweet and 'salty' snacks consumed. 
10. The frequency of consumption of fish, poultry, red meat, eggs, white bread, whole-grain bread, potatoes, rice, fruits, vegetables, fruit juices, soft drinks, beverages and of traditionally cooked Greek meals.

The main categories (including their subcategories) of the above-mentioned foods and beverages consumed were coded as follows.

1. 'Dairy products': all kind of milks, all types of yoghurts, and all types of cheeses.

2. Snack food was divided in two main categories: 'salty' snacks (like fast-food items such as hamburger, one piece of pizza, hot dog, toast, one piece of cheese pie, one piece of spinach pie, all kind of potato chips, savoury snacks, popcorn) and 'sweet' foods (like ice cream, milk shake, all kinds of chocolates, croissant, cakes, biscuits).

3. All types of soft drinks (still, fizzy, diet, etc.).

4. Fruit juices (fresh, or ready to drink, 100\% juice without added sugars).

5. Beverages (tea, chamomile, etc.).

6. Traditionally cooked Greek foods (moussaka, beans, etc.).

When the FFQ was completed, subjects indicated how often, on average, they consumed the amount of each food item. The categorisation of the frequency of consumption was not uniform and varied according to the type of food/drink consumed.

Information on the frequency and duration of physical activities during leisure time (walking, playing), the participation in extracurricular sports outside school (brisk swimming, basketball, football, etc.) and on the amount of time spent on sedentary activities (watching television, working on a computer, playing video games) was retrieved from the study's questionnaire.

The study, including data collection, was approved by the Ethics Committee of the Vyronas Health Center.

\section{Statistical analysis}

Continuous variables are presented as mean and standard deviation, while categorical variables are presented as absolute and relative frequencies. Pearson's correlation coefficient was used in order to measure associations between the continuous variables, while contingency tables with calculation of the $\chi^{2}$ test evaluated associations between the categorical variables. Relationships between groups of intake and BMI were tested by the use of ANOVA. Then, we used: (i) multiple linear regression analysis to evaluate the relationship between consumption of breakfast cereals and BMI; and (ii) logistic regression analysis to determine to what extent consumption of breakfast cereals was associated with the likelihood of overweight or obesity (we combined these categories because of the small number of persons in each group). The estimate of the relative risks of over- weight or obesity was performed by calculating the OR and the corresponding $95 \% \mathrm{CI}$. Deviance residuals were calculated in order to evaluate the model's goodness-offit. All reported probability values ( $P$ values) were based on two-sided tests and compared with a statistically significant level of $5 \%$. The Statistical Package for the Social Sciences statistical software package version 12 (SPSS Inc., Chicago, IL, USA) was used for all calculations.

\section{Results}

Overall, $4 \cdot 7 \%$ of boys and $1 \cdot 7 \%$ of girls were defined as obese, whereas $19 \cdot 4 \%$ of boys and $13 \cdot 2 \%$ of girls were overweight. Dietary analysis revealed that $41.9 \%$ of boys and $40.7 \%$ of girls eat breakfast daily; while $39.7 \%$ of boys and $45.9 \%$ of girls almost skip breakfast (never/rare and less than 1-2 times/week). The distribution of the frequency of breakfast consumption by sex is presented in Table 1 .

Moreover, dietary analysis showed that $73.6 \%$ of boys and $68.8 \%$ of girls report consumption of cereals for breakfast among other foods. Boys consumed cereals for breakfast more frequently than girls $(P=0 \cdot 014)$. The distribution of breakfast cereals consumption by age group is presented in Table 2 .

Table 3 illustrates the distribution of the various foods consumed during breakfast in our study sample. It was observed that milk and cereals were the main foods consumed for breakfast in both genders. However, only $20 \cdot 7 \%$ of boys and $15 \cdot 5 \%$ of girls reported to consume cereals as a first choice for breakfast. Furthermore, of those cereal consumers, $42.5 \%$ of boys and $49 \cdot 0 \%$ of girls reported that they consume pre-sweetened breakfast cereals.

Figure 1 illustrates BMI levels by frequency of consumption of breakfast cereals. Post hoc comparisons (Bonferroni corrected) showed that, compared with no or rare consumption, daily intake or the intake of more than two daily servings of cereals for breakfast was associated with lower BMI levels in boys and girls $(P<0 \cdot 01)$. Multiple regression analysis revealed that consumption of breakfast cereals was associated with lower BMI in boys $(P=0.08)$ and girls $(P=0 \cdot 019)$, irrespective of age and physical activity status. Table 4 shows mean values of BMI, adjusted for age, sex and physical activity, by frequency consumption of cereals. Multiple logistic

Table 1 Frequency of breakfast consumption among children who participated in the VYRONAS study

\begin{tabular}{|c|c|c|c|c|c|c|}
\hline \multirow[b]{2}{*}{ How often do you eat breakfast? } & \multicolumn{2}{|c|}{ Boys } & \multicolumn{2}{|c|}{ Girls } & \multicolumn{2}{|c|}{ Overall } \\
\hline & $\%$ & $n$ & $\%$ & $n$ & $\%$ & $n$ \\
\hline Never/rare & $19 \cdot 3$ & 207 & 22.9 & 240 & $21 \cdot 1$ & 447 \\
\hline 1-2 times/week & $20 \cdot 4$ & 218 & $23 \cdot 0$ & 241 & $21 \cdot 7$ & 459 \\
\hline 3-4 times/week & $11 \cdot 1$ & 119 & $7 \cdot 7$ & 81 & $9 \cdot 4$ & 200 \\
\hline 5-6 times/week & $7 \cdot 3$ & 78 & $5 \cdot 6$ & 59 & $6 \cdot 5$ & 137 \\
\hline Daily & 41.9 & 448 & $40 \cdot 7$ & 426 & $41 \cdot 3$ & 874 \\
\hline
\end{tabular}


Table 2 Consumption of breakfast cereals among children who participated in the VYRONAS study

\begin{tabular}{lcc}
\hline & \multicolumn{2}{c}{ Do you eat cereals for breakfast among other foods? } \\
\cline { 2 - 3 } Gender/age & No $(\%)$ & Yes $(\%)$ \\
\hline Boys & & \\
12 years & $17 \cdot 7$ & $82 \cdot 3$ \\
13 years & $24 \cdot 8$ & $75 \cdot 2$ \\
14 years & $20 \cdot 1$ & $79 \cdot 9$ \\
15 years & $27 \cdot 5$ & $72 \cdot 5$ \\
16 years & $34 \cdot 5$ & $65 \cdot 5$ \\
17 years & $42 \cdot 6$ & $57 \cdot 4$ \\
18 years & $28 \cdot 6$ & $71 \cdot 4$ \\
Total & $26 \cdot 4$ & $73 \cdot 6$ \\
Girls & & \\
12 years & $23 \cdot 4$ & $76 \cdot 6$ \\
13 years & $23 \cdot 8$ & $76 \cdot 2$ \\
14 years & $30 \cdot 0$ & $70 \cdot 0$ \\
15 years & $33 \cdot 1$ & $66 \cdot 9$ \\
16 years & $37 \cdot 5$ & $62 \cdot 5$ \\
17 years & $38 \cdot 3$ & $61 \cdot 7$ \\
18 years & $64 \cdot 3$ & $35 \cdot 7$ \\
Total & $31 \cdot 2$ & $68 \cdot 8$ \\
\hline
\end{tabular}

Table 3 Foods consumed during breakfast among children who participated in the VYRONAS study

\begin{tabular}{lccc}
\hline $\begin{array}{l}\text { Which food do you consume during } \\
\text { your breakfast as a first choice? }\end{array}$ & $\begin{array}{c}\text { Boys } \\
(\%)\end{array}$ & $\begin{array}{c}\text { Girls } \\
(\%)\end{array}$ & $\begin{array}{c}\text { Overall } \\
(\%)\end{array}$ \\
\hline Milk & $59 \cdot 4$ & $58 \cdot 8$ & $59 \cdot 1$ \\
Cereals & $20 \cdot 7$ & $15 \cdot 5$ & $18 \cdot 1$ \\
Fruit juice & $7 \cdot 2$ & $9 \cdot 3$ & $8 \cdot 2$ \\
Cake & $3 \cdot 7$ & $5 \cdot 1$ & $4 \cdot 4$ \\
Butter/margarine & $3 \cdot 9$ & $4 \cdot 6$ & $4 \cdot 3$ \\
Bread & $2 \cdot 2$ & $3 \cdot 1$ & $2 \cdot 6$ \\
Honey & $2 \cdot 5$ & $2 \cdot 5$ & $2 \cdot 5$ \\
Yoghurt & $0 \cdot 4$ & $1 \cdot 2$ & $0 \cdot 8$ \\
\hline
\end{tabular}

regression analysis revealed that consumption of cereals as a first choice for breakfast was associated with 33\% (95\% CI $14 \%$, 48\%) lower likelihood of overweight/obesity, irrespective of age, sex and physical activity status (Table 5).

Furthermore, consumption of pre-sweetened breakfast cereals was reported by $43 \%$ of boys and $49 \%$ of girls. Intake of pre-sweetened cereals was associated with lower BMI compared with non-pre-sweetened or no intake of cereals in both genders (Fig. 2, $P<0 \cdot 001$ ). It is of interest that BMI levels did not differ between the groups of adolescents who reported consumption of non-pre-sweetened cereals and those who reported no consumption of cereals $(P>0 \cdot 05)$.

\section{Discussion}

The present study showed that about one out of five boys and girls consumed cereals at breakfast. Consumption of breakfast cereals was associated with lower BMI levels and lower likelihood of overweight/obesity in both genders. Some $19 \cdot 4 \%$ of boys and $13 \cdot 2 \%$ of girls were defined as overweight, whereas $4.7 \%$ of boys and $1.7 \%$
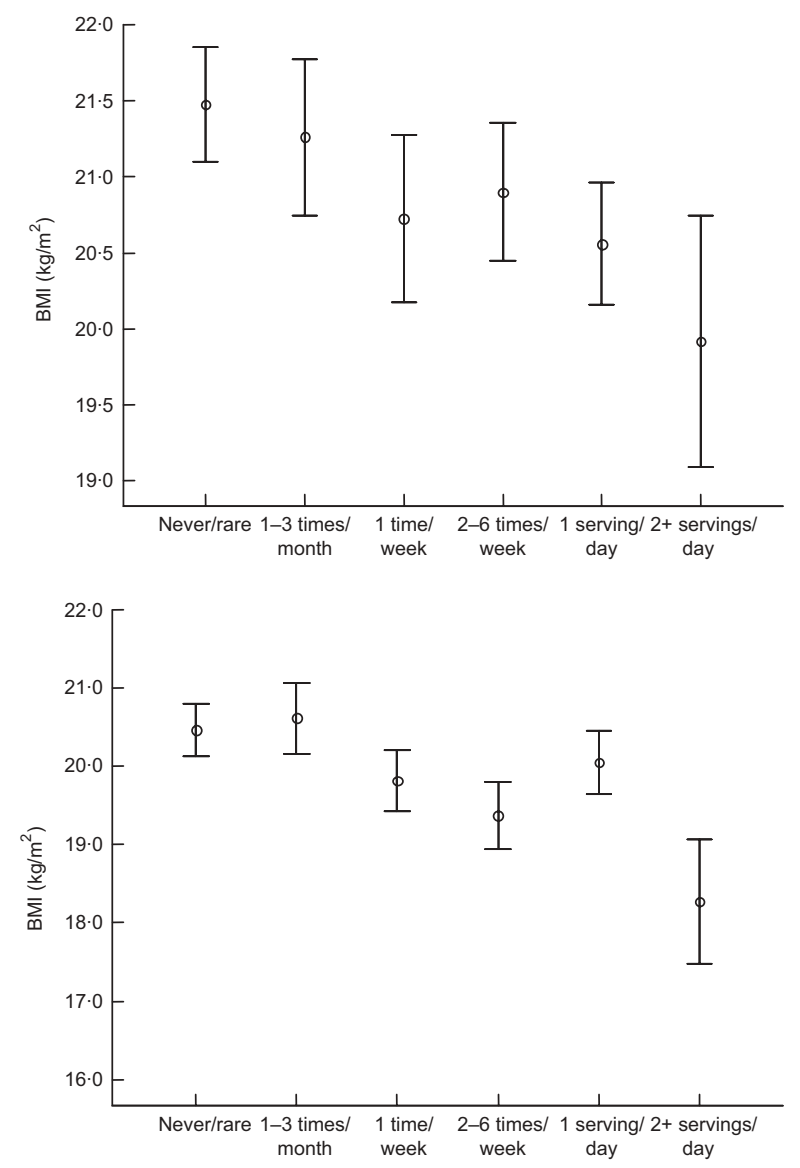

Fig. $1 \mathrm{BMI}$ and frequency of consumption of breakfast cereals in boys (top) and girls (bottom) who participated in the VYRONAS study. Values are means with their $95 \% \mathrm{Cl}$ represented by vertical bars

Table 4 Mean BMI levels by frequency of breakfast cereals consumption among children who participated in the VYRONAS study

\begin{tabular}{lll}
\hline & \multicolumn{2}{c}{$\mathrm{BMI}\left(\mathrm{kg} / \mathrm{m}^{2}\right)$} \\
\cline { 2 - 3 } Gender/breakfast cereals consumption & Mean & $\mathrm{SD}$ \\
\hline Boys & & \\
Never/rare & $21 \cdot 5$ & $3 \cdot 15$ \\
1-3 times/month & $21 \cdot 2$ & $3 \cdot 63$ \\
1 time/week & $20 \cdot 7$ & $3 \cdot 15$ \\
2-6 times/week & $20 \cdot 8$ & $2 \cdot 96$ \\
Daily & $20 \cdot 5$ & $3 \cdot 33$ \\
>2 daily servings & $20 \cdot 1$ & $3 \cdot 31$ \\
Girls & & \\
Never/rare & $20 \cdot 6$ & $2 \cdot 91$ \\
1-3 times/month & $20 \cdot 6$ & $3 \cdot 07$ \\
1 time/week & $19 \cdot 8$ & $2 \cdot 49$ \\
2-6 times/week & $19 \cdot 4$ & $2 \cdot 72$ \\
Daily & $19 \cdot 9$ & $2 \cdot 70$ \\
>2 daily servings & $18 \cdot 3$ & $2 \cdot 17$ \\
\hline
\end{tabular}

of girls were obese. These findings are not in accordance with the findings of other investigators who conducted studies $^{(3,4)}$ in Greek adolescents, probably because these variations are a result of study design or measurement sensitivity or sociodemographic factors ${ }^{(26)}$. In addition, as expected, the results of the present study revealed that 
Table 5 Results from multiple logistic regression analysis that evaluated the consumption of breakfast cereals and the likelihood of being overweight/obese among schoolchildren who participated in the VYRONAS study

\begin{tabular}{lccr}
\hline & OR & $95 \%$ Cl & $P$ \\
\hline Age (per year) & 1.259 & $1.172,1.353$ & 0.001 \\
Girls v. boys & 0.510 & $0.401,0.650$ & 0.001 \\
Physical activity level (1-5) & 0.764 & $0.598,0.976$ & 0.031 \\
Consumption of cereals during breakfast (yes v. no) & 0.671 & $0.522,0.862$ & 0.002 \\
\hline
\end{tabular}
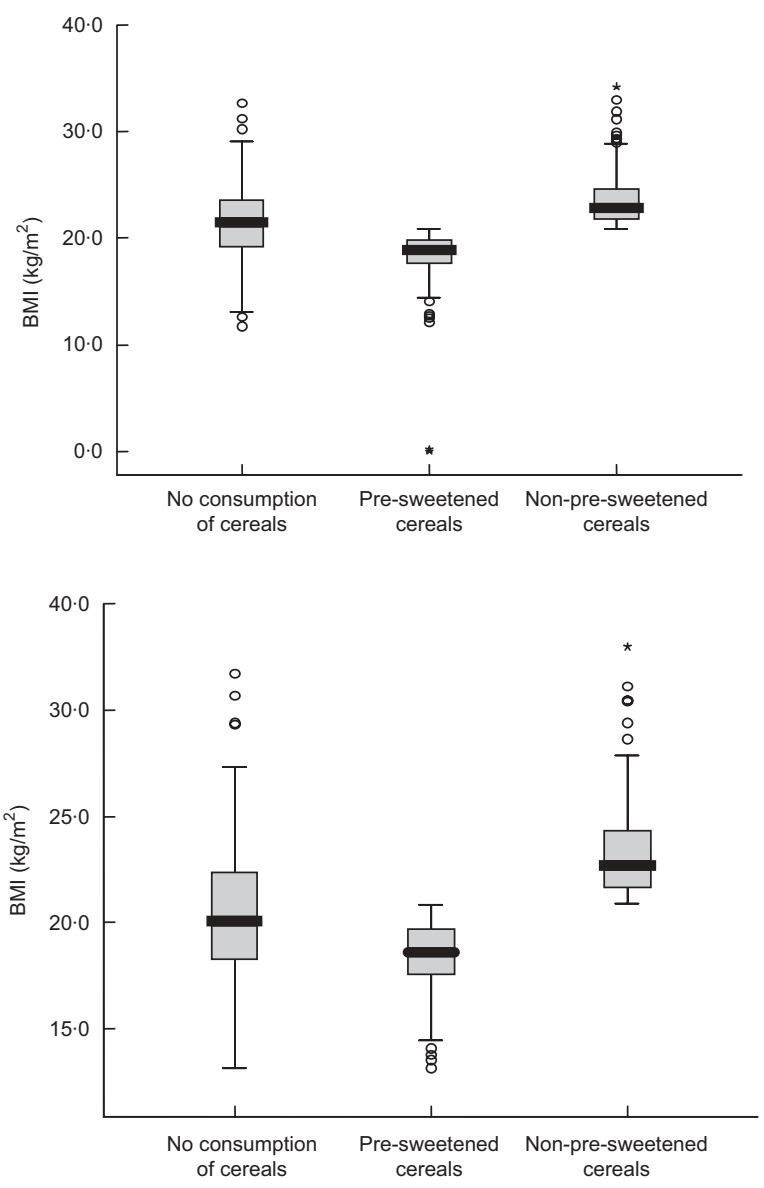

Fig. 2 Box and whisker plot of BMI in relation to consumption and type of breakfast cereals in boys (top) and girls (bottom) who participated in the VYRONAS study. Asterisks above or below the box indicate cases (adolescents) that are outliers

the prevalence of overweight and obesity was higher among male than female adolescents.

Also, the results of the VYRONAS study revealed that $21 \cdot 1 \%$ of adolescents skip breakfast. The literature suggests that breakfast skipping is highly prevalent in the USA and Europe (10-30\%) depending on age group, population and definition. The figure of $21 \cdot 1 \%$ from the present study is similar to that reported by other investigators $^{(10,11)}$, confirming the international trend of adolescents to skip breakfast.

However, it is worth mentioning that when we combine the percentage of the occasional breakfast-eaters (1-2 times/week) with that of breakfast skippers, the total figure is double - reaching the level of $43 \%$, which is considerably high and most alarming.

The consumption of breakfast is one dietary pattern that is promoted as providing positive nutritional benefits ${ }^{(17)}$. Notwithstanding, Cho et al. ${ }^{(11)}$ suggested that the relationship between breakfast and positive health outcomes may be due to the specific foods consumed at breakfast, rather than breakfast per se. Thus, in the VYRONAS study we evaluated the relationship of cereal consumption for breakfast with BMI in adolescents. In particular, we found that $20 \cdot 7 \%$ of boys and $15.5 \%$ of girls consume cereals as a first choice for their breakfast. This is a lower figure than the one which has been reported by other investigators, demonstrating clear geographical differences in consumption patterns of breakfast foods. For example, this percentage is far below that reported by Nicklas et al. ${ }^{(27)}$ in a study conducted among 567 students in 9th grade, where 30\% ate RTEC based on a $24 \mathrm{~h}$ dietary recall. In addition, this pattern of consumption is not similar to that reported by the Bogalusa Heart Study ${ }^{(14)}$, since although in that study $21 \%$ of the 10-year-old RTEC consumers (sweetened or unsweetened) reported consumption at some point during the day only $63 \%$ of them consumed RTEC at breakfast, within a $24 \mathrm{~h}$ period. Furthermore, the findings of the present work are not in accordance with the results reported by van den Boom et $a l^{(18)}$, where $49 \cdot 8 \%$ of the studied population (aged 2 to 24 years) reported eating RTEC. Regarding the frequency of consumption of RTEC, in the VYRONAS study $18 \%$ of the school adolescents ate RTEC at least once per week, which is not in accordance with the findings reported by Kafatos et al. ${ }^{(13)}$ where $43 \%$ of adolescents ate RTEC at least once per week. Finally, we demonstrated that RTEC consumption decreased significantly as girls became older, which is in accordance with the findings of National Heart, Lung, and Blood Institute Growth and Health Study ${ }^{(19)}$ in girls.

Regarding the inverse relationship between breakfast RTEC consumption and BMI found in the VYRONAS study, this finding is consistent with the results of other studies $^{(11,20,21)}$ conducted in adults, while Song et al. ${ }^{(20)}$ suggested that RTEC consumption predicted weight status in women but not in men. In agreement with that reported by other international studies ${ }^{(12,13,17-19)}$ conducted in children and adolescents, the present work shows an inverse relationship between RTEC consumption and BMI. In particular, Albertson et al. ${ }^{(17)}$ suggested that the 
consumption of RTEC at breakfast should be encouraged as a component of an eating pattern that promotes the maintenance of healthy body weight and nutrient intakes in children. Furthermore Barton et al. ${ }^{(19)}$ reported that, beyond the relationship between cereal and BMI, cereal consumption had positive effects on nutrient intake in adolescent girls, resulting in diets significantly lower in fat and cholesterol and that RTEC made significant contributions to nutrient intakes in the diets of the adolescent girls studied. Moreover, a negative association between BMI and frequency of RTEC was also reported by Kafatos et al. ${ }^{(13)}$ in a study sample of Greek adolescents.

Another beneficial effect of RTEC consumption is that the majority of the adolescents consume them with milk ${ }^{(13,14,18)}$, which is in accordance with the results of the VYRONAS study where it was shown that milk and cereals were the main foods consumed at breakfast in both genders.

The findings in the VYRONAS study concerning the inverse association of pre-sweetened breakfast cereals with BMI could be justified by the results of a study ${ }^{(28)}$ which supported that added sugars in the diet were associated with increased servings of grains.

Although the present study does not give quantitative data, one could speculate that the added sugars contained in the pre-sweetened cereals may lead to increased consumption of grains with a probable beneficial effect on BMI status.

Also, another possible explanation relevant to the inverse association of pre-sweetened breakfast cereals with BMI could be that teenagers who are weightconscious may skip breakfast in general and that teenagers who are slimmer may readily consume pre-sweetened cereals because they are not calorie-watchers. Additionally, results from the VYRONAS study demonstrated that, compared with no or rare consumption, daily intake or the intake of more than two daily servings of cereals for breakfast was associated with lower BMI levels in both genders, a finding which agrees with the results of Albertson et $a l^{(17)}$ where children who consumed RTEC eight or more times in 2 weeks had significantly lower BMI than those who consumed three or fewer servings in $14 \mathrm{~d}$.

The relationship between the consumption of RTEC and BMI is difficult to explain. Several explanations could be proposed for the association between cereal consumption and body weight. First, RTEC consumption may be a marker for other healthful lifestyle factors practised by adolescents $^{(17)}$. For example, it has been reported ${ }^{(17)}$ that breakfast consumers are less likely to snack during the morning, a habit which if repeated daily could lead to over-consumption of energy. Second, as the results showed, RTEC are most frequently consumed with milk, which is a good source of dietary Ca. Research ${ }^{(29)}$ shows that dietary Ca modulates circulating calcitriol (1,25-dihydroxyvitamin D) levels that in turn regulate intracellular $\mathrm{Ca}$ which affects fat metabolism in human adipocytes. A portion of this additional anti-obesity bioactivity is attributable to the inhibition of angiotensin-converting enzyme activity by dairy foods and to the rich concentration of branched-chain amino acids which act synergistically with Ca to attenuate adiposity ${ }^{(29)}$. Thus, it is possible that the proposed ${ }^{(29)}$ mechanism could be a factor in contributing to the better intake regulation of frequent cereal-eaters ${ }^{(17)}$. Furthermore, literature ${ }^{(30)}$ has shown that RTEC is an important food source of whole grains, which has been found ${ }^{(23,24)}$ to be inversely associated with obesity, and that cereals and cereal products are the main sources of dietary fibre ${ }^{(9)}$ with an undoubtedly positive effect on BMI status ${ }^{(31)}$.

\section{Limitations}

The present study, as a cross-sectional one, has several limitations. First, no causal relationships can be proposed. The presented findings may only be valuable for stating hypotheses. Dietary habits were evaluated once; thus, seasonal variability could not be taken into account. Furthermore, over- or under-reporting of foods or food groups consumed by the adolescents may bias the reported results. Also, consideration should be given to the fact that there is a lack of information on the exact serving sizes and on the level of the added sugars in the pre-sweetened cereals.

In addition, the Vyronas area does not represent the entire country, or even more other countries in Europe, the USA, etc.

\section{Conclusions}

The results of the VYRONAS study highlight an inverse association between pre-sweetened breakfast cereals (equivalent to sweetened breakfast cereals in the USA and UK) and BMI in adolescents. Taking into consideration the raising prevalence of overweight ${ }^{(1)}$ and the popularity of breakfast cereals among children and adolescents, especially in Westernised countries ${ }^{(17,18)}$, it could be of public health benefit to include RTEC consumption in campaigns for obesity prevention, especially in children. Since our findings reflect those shown in other population groups globally ${ }^{(11,17,19,32)}$, a solid basis for public health professionals could be built when issuing advice on weight management in order to encourage the consumption of breakfast cereals as part of a weightmanagement strategy helping to aid weight control.

\section{Acknowledgements}

There are no conflicts of interest. The VYRONAS study was partly funded by Cereal Partners Worldwide. Author contributions $(\mathrm{A}=$ study design, $\mathrm{B}=$ data collection, $\mathrm{C}=$ statistical analysis, $\mathrm{D}=$ data interpretation, $\mathrm{E}=$ manuscript preparation, $F=$ literature search, $G=$ funds collection): R.I.K. (ACDEF); D.B.P. (ACDE); A.Z. (F); C.M. (B); A.A. (B); C.L. (F); Y.T. (AF); A.M. (ABF). The authors would like to thank all adolescents who participated in 
this study and the field investigators who performed all data collection: V. Gizlis, E. Konstantinou, M. Papathanasiou, P. Daskalakis, K. Marayannis, K. Kintzolakis, C. Spentzos and Y. Lentzas, as well as the Municipality of Vyronas that made this survey feasible.

\section{References}

1. Daniels SR, Arnett DK, Eckel RH, Gidding SS, Hayman LL, Kumanyika S, Robinson TN, Scott BJ, Jeor SSt \& Williams CL (2005) Overweight in children and adolescents: pathophysiology, consequences, prevention, and treatment. Circulation 111, 1999-2012.

2. Kapantais E, Tzotzas T, Ioannidis I, Mortoglou A, Bakatselos S, Kaklamanou M, Lanaras L \& Kaklamanos I (2006) First national epidemiological survey on the prevalence of obesity and abdominal fat distribution in Greek adults. Ann Nutr Metab 50, 330-338.

3. Karayiannis D, Yannakoulia M, Terzidou M, Sidossis LS \& Kokkevi A (2003) Prevalence of overweight and obesity in Greek school-aged children and adolescents. Eur J Clin Nutr 57, 1189-1192.

4. Krassas GE, Tzotzas T, Tsametis C \& Konstantinidis T (2001) Prevalence and trends in overweight and obesity among children and adolescents in Thessaloniki, Greece. J Pediatr Endocrinol Metab 14, 1310-1326.

5. Magkos F, Manios Y, Christakis G \& Kafatos AG (2006) Agedependent changes in body size of Greek boys from 1982-2002. Obesity 14, 289-294.

6. Arvaniti F, Panagiotakos DB, Pitsavos C, Zampelas A \& Stefanidis C (2006) Dietary habits in a Greek sample of men and women: the ATTICA study. Cent Eur J Public Health 14, 74-77.

7. Magkos F, Piperkou I, Manios Y et al. (2006) Diet, blood lipid profile and physical activity patterns in primary school children from a semi-rural area of Greece. J Hum Nutr Diet 19, 101-112.

8. Yiannakoulia M, Karayiannis D, Terzidou M, Kokkevi A \& Sidossis LS (2004) Nutrition-related habits of Greek adolescents. Eur J Clin Nutr 58, 580-586.

9. Suter PM (2005) Carbohydrates and dietary fiber. Handb Exp Pharmacol 170, 231-261.

10. Rampersaud GC, Pereira MA, Girard BL, Adams J \& Metzl JD (2005) Breakfast habits, nutritional status, body weight, and academic performance in children and adolescents. J Am Diet Assoc 105, 743-760.

11. Cho S, Dietrich M, Brown CJP, Clark CA \& Block G (2003) The effect of breakfast type on total daily energy intake and body mass index: results from the third National Health and Nutrition Examination Study (NHANES III). J Am Coll Nutr 22, 296-302.

12. Gibson SA \& O'Sallivan KR (1995) Breakfast cereal consumption patterns and nutrient intakes of British schoolchildren. $J$ R Soc Health 115, 366-370.

13. Kafatos A, Linardakis M, Bertsias G, Mammas I, Fletcher R \& Bervanaki F (2005) Consumption of ready-to-eat cereals in relation to health and diet indicators among school adolescents in Crete, Greece. Ann Nutr Metab 49, 165-172.

14. Nicklas TA, O'Neil CE \& Berenson GS (1998) Nutrient contribution of breakfast, secular trends, and the role of ready-to-eat cereals: a review of data from the Bogalusa Heart Study. Am J Clin Nutr 67, 757S-763S.

15. Preziosi P, Galan P, Decheeger M, Yacoub N, Drewnowski A \& Hereberg S (1999) Breakfast type, daily nutrient intakes, and vitamin and mineral status of French children, adolescents and adults. $J$ Am Coll Nutr 18, 171-178.

16. Gibson S (2003) Micronutrient intakes, micronutrient status and lipid profiles among young people consuming different amounts of breakfast cereals: further analysis of data from the National Diet and Nutrition Survey of Young People aged 4 to 18 years. Public Health Nutr 6, 815-820.

17. Albertson AM, Anderson GH, Crockett SJ \& Goebel MT (2003) Ready-to-eat cereal consumption: its relationship with BMI and nutrient intake of children aged 4 to 12 years. J Am Diet Assoc 103, 1613-1619.

18. van den Boom A, Serra-Majem L, Ribas L, Ngo J, Perez-Rodrigo C, Aranceta J \& Fletcher R (2006) The contribution of ready-to-eat cereals to daily nutrient intake and breakfast quality in a Mediterranean setting. $J \mathrm{Am}$ Coll Nutr 25, 135-143.

19. Barton BA, Eldridge AL, Thompson D, Affenito SG, Striegel-Moore RH, Franko DL, Albertson AM \& Crockett SJ (2005) The relationship of breakfast and cereal consumption to nutrient intake and body mass index: the National Heart, Lung, and Blood Institute Growth and Health Study. J Am Diet Assoc 105, 1383-1389.

20. Song WO, Chun OK, Obayashi S, Cho S \& Chung CE (2005) Is consumption of breakfast associated with body mass index in US adults? J Am Diet Assoc 105, 1373-1382.

21. Bazzano LA, Song Y, Bubes V, Good CK, Manson JE \& Liu S (2005) Dietary intake of whole and refined grain breakfast cereals and weight gain in men. Obes Res 13, 1952-1960.

22. Ortega RM, Requejo AM, Lopez-Sobaler AM, Quintas ME, Andres P, Redondo MR, Navia B, Lopez-Bonilla MD \& Rivas $\mathrm{T}$ (1998) Differences in the breakfast habits of overweight/ obese and normal weight schoolchildren. Int J Vitam Nutr Res 68, 125-132.

23. Liu S, Willett WC, Manson JE, Hu FB, Rosner B \& Colditz G (2003) Relation between changes in intakes of dietary fibre and grain products and changes in weight and development of obesity among middle-aged women. Am J Clin Nutr 78, 920-927.

24. Koh-Banerjee P, Franz M, Sampson L, Liu S, Jacobs DR Jr, Spiegelman D, Willett W \& Rimm E (2004) Changes in whole-grain, bran and cereal fiber consumption in relation to 8-y weight gain among men. Am J Clin Nutr 80, $1237-1245$.

25. Cole TJ, Bellizzi MC, Flegal KM \& Dietz WH (2000) Establishing a standard definition for child overweight and obesity worldwide: international survey. BMJ 320, 1240-1243.

26. Kafatos A, Codrington CA, Linardakis M (2005) Obesity in childhood: the Greek experience. Nutrition and fitness: obesity, the metabolic syndrome, cardiovascular disease, and cancer in world. Rev Nutr Diet, pp. 27-35 [AP Simopoulos, editor]. Basel: Karger.

27. Nicklas TA, McQuerrie A, Fastnaught C \& O'Neil CE (2002) Efficiency of breakfast consumption patterns of ninth graders: nutrient-to-cost comparisons. J Am Diet Assoc 102, 226-233.

28. Forshee RA \& Storey ML (2001) The role of added sugars in the diet quality of children and adolescents. J Am Coll Nutr 20, 32-43.

29. Zemel MB (2005) The role of dairy foods in weight management. J Am Coll Nutr 24, S537-S546.

30. Harnack L, Walters SA \& Jacobs DR Jr (2003) Dietary intake and food sources of whole grains among US children and adolescents: data from the 1994-1996 Continuing Survey of Food Intakes by Individuals. J Am Diet Assoc 103, 1015-1019.

31. Lairon D, Arnault N, Bertrais S, Planells R, Clero E, Hercberg S \& Boutron-Ruault M-C (2005) Dietary fibre intake and risk factors for cardiovascular disease in French adults. Am J Clin Nutr 82, 1185-1194.

32. De la Hunty A \& Ashwell M (2007) Are people who regularly eat breakfast cereals slimmer than those who don't? A systematic review of the evidence. Nutr Bull 32, $118-128$. 